\title{
Violência contra crianças e adolescentes e a atuação do psicólogo
}

\author{
Violence against children and adolescents and the role of the psychologist \\ Christiano Thomaz de Almeida Monteiro Barbosa ${ }^{\dagger *}$, Fátima Niemeyer da Rocha
}

Como citar esse artigo. BARBOSA, C.T.A.M; DA ROCHA, F.N. Violência contra a criança e ao adolescente e a atuação do psicólogo. Revista Mosaico, v.11, n.1, p. $161-168,2020$.

\author{
Resumo
}

A violência contra crianças e adolescentes, procedente desde os tempos da colonização, ainda é uma prática alarmante, ocasionando enormes distúrbios que podem se prolongar até a vida adulta. A atuação do psicólogo é significativa para a prevenção e a minimização dos danos às vítimas, pois a violência é um episódio complexo e multifatorial, sendo muitas vezes difícil de elucidar. Este artigo visou discutir acerca das possibilidades de atuação e do papel do psicólogo frente à violência perpetrada contra crianças e adolescentes. Numa revisão da literatura especializada no tema, parte da caracterização dos tipos de violência, aborda como essa se apresenta e finaliza com as possibilidades de atuação do psicólogo no atendimento à vítima. A Organização Mundial da Saúde classifica a violência em quatros grupos: violência física, violência psicológica, violência sexual e negligência e abandono. A violência pode gerar inúmeras consequências negativas na vida da criança e do adolescente, incluindo o transtorno de estresse pós-traumático. A prática da psicologia propõe resguardar e atenuar os males oriundos dessa violência.

Palavras-chave: Violência; Criança; Adolescente; Atuação do Psicólogo.

\begin{abstract}
Since the colonization time, violence against children and adolescents, has still been an alarming practice, causing a lot of disturbances that could prolong till adulthood. The psychologists' role is significant in preventing and minimizing harm to victims, as violence is a complex and multifactorial episode and it is difficult to elucidate. This article aimed to discuss about the possibilities of action and the role of the psychologist in the face of violence perpetrated against children and adolescents. In a review of the specialized literature on the subject, part of the characterization of the types of violence, addresses how to it presents itself and ends with the possibilities of the psychologist's performance in assisting the victim. The World Health Organization classifies violence into four groups: physical violence, psychological violence, sexual violence, and neglect and abandonment. Violence can have numerous negative consequences on the lives of children and adolescents, including Posttraumatic Stress Disorder. The practice of psychology proposes to safeguard and mitigate the evils arising from this violence.

Keywords: Violence; Children; Adolescents; PTSD; Psychologist's role
\end{abstract}

\section{Introdução}

Desde a colonização portuguesa até os dias atuais, tanto as crianças quanto os adolescentes têm sido vítimas de violência, de exploração, de exclusão e de maus tratos em seu cotidiano. Esse processo se inicia em Portugal, com o recrutamento de jovens pobres vindos de orfanatos e através do sequestro de crianças judias, para que fizessem parte da tripulação das naus. Essas crianças, além de servirem de mão de obra, contribuíam com a obrigatoriedade de manter um grande número de marinheiros em alto-mar. Como a alimentação nos navios era escassa, se aproveitavam também deles consumirem uma quantidade menor de alimentos e, quando ocorriam os naufrágios, essas crianças eram abandonadas à mercê das tempestades.
Durante a viagem podiam ser violentadas sexualmente por toda a tripulação e, ao chegarem em terra, eram obrigadas a se casarem com quem a Coroa ordenasse (RAMOS, 2002; VENÂNCIO, 2002).

No Brasil, segundo Góes e Florentino (2002), durante a época da escravidão anterior a Lei do Ventre Livre, a criança, filha de escravos, também era considerada escrava; o período da sua infância se estendia somente enquanto não possuía a força ou a destreza necessária para realizar as tarefas. Por volta dos sete ou oito anos já era incluída na comunidade escrava, devendo obediência aos seus senhores e estando sujeita aos castigos corporais e humilhações.

Em 1871 foi promulgada a Lei do Ventre Livre que, apesar de permitir a liberdade infantil naquele sistema escravocrata, possibilitou também o desencadeamento de um processo de abandono nas ruas das crianças,

\footnotetext{
Afiliação dos autores:

${ }^{\dagger}$ Graduando, Curso de Psicologia, Universidade de Vassouras, Vassouras, RJ, Brasil

* Doutora em Psicologia, Professora Titular, Curso de Psicologia, Universidade de Vassouras, Vassouras, RJ, Brasil
}

* Email de correspondencia: christiano.almeida@hotmail.com 
filhas de escravos, que eram libertadas. Eram crianças que, através do trabalho informal ou da prática de atos ilícitos, passaram a prover seu sustento e o de suas famílias, gerando um fenômeno psicossocial, em que essas crianças e adolescentes perderam suas referências e bases familiares e culturais, imprescindíveis para seu desenvolvimento psíquico e social (ALBERTO, 2002).

Já no início do século XX, com o processo de industrialização, crianças e adolescentes passaram a trabalhar ativamente em fábricas, oficinas e indústrias, em condições insalubres e muitas vezes perigosas. Além do mal-estar psicológico, eram suscetíveis a acidentes, que resultavam em inúmeras sequelas e amputações e, em casos extremos, poderiam levar à morte (MOURA, 2009).

Atualmente, a violência contra crianças e adolescentes éconsideradaum problema de saúdepública reconhecido pela Organização Mundial de Saúde (OMS), que afeta todos os anos milhões de crianças, famílias e comunidades. Trata-se de um processo históricosocial que provoca um grande impacto nos processos de desenvolvimento pessoal. No Brasil, com a criação do Estatuto da Criança e do Adolescente (ECA), com a Lei 8.069 de 1990, crianças e adolescentes passaram a ser considerados como sujeitos de diretos, o que lhes concedeu prioridades. Essa legislação tornou obrigatória a notificação de casos suspeitos ou confirmados de violência contra crianças e adolescentes e estabeleceu penas para profissionais - como médicos, professores e responsáveis por estabelecimentos de saúde e educação - que não os denunciem (GONÇALVES; FERREIRA, 2002; KRUG et al., 2002).

Como informa Ferreira (2002), a violência é um fenômeno complexo e multifatorial, o que torna difícil de ser explicada através de uma visão linear de causa e efeito, sendo vista como uma consequência de um contexto e de uma dinâmica sociocultural e política. Pode ser gerada por relações de poder já estabelecidas, onde se entende como natural o mais forte dominar o mais fraco.

A OMS descreve a violência como o uso intencional de força e poder físico, em tom de ameaça ou fato, contra si, contra outras pessoas, contra um grupo ou comunidade, que possa resultar ou não em lesão, morte, prejuízo psicológico, deficiência de desenvolvimento ou privação (KRUG et al. 2002). No Brasil, o Ministério da Saúde a define como um evento provocado através de ações causadas por indivíduos, grupos, classes e nações, que resultem em danos físicos, emocionais, morais e/ ou espirituais a si ou a terceiros, de origem intencional. (BRASIL, 2001)

Grande parte das definições de violência incorpora dois elementos centrais, a evidência de conduta prejudicial à criança e a presença de sérios danos provenientes dessas ações. Essas experiências interferem significativamente no desenvolvimento futuro dessas vítimas, com prejuízos que variam desde comportamentos não adaptativos e déficits de atenção a transtornos mentais graves, como por exemplo: transtorno de hiperatividade, problemas de aprendizado escolar, transtorno de conduta e abuso de substâncias químicas (REICHENHEIM et al., 2011).

Estudos relacionam episódios de violência infantil com algumas questões importantes, como relações familiares desarmônicas, condições sociais desfavoráveis dos familiares (como pobreza, promiscuidade, desemprego e condições ruins de moradia), baixo nível de escolaridade dos pais e responsáveis, privação econômica, famílias cujos pais sofreram algum tipo de abuso ou negligência e portadores de transtornos psiquiátricos. Além disso, existem também os elementos de vulnerabilidade infantil, como bebês prematuros, crianças com retardo mental ou casos de adoção (REICHENHEIM et al., 2011; HUSSEY; CHANG; KOTCH, 2006).

A violência contra crianças deve ser encarada como um fenômeno articulado, um problema estrutural e social no qual a sociedade está exposta. Deve ser reconhecida como um problema de saúde pública e que possui altas taxas de morbimortalidade. E em função de diminuir as consequências geradas pela violência fazse necessário um maior investimento em estratégias de prevenção na primeira infância, através da ação conjunta dos setores da saúde, educação, serviços sociais, justiça e política (DOSSI et al., 2008; FERRIANI; BERTOLUCCI; SILVA, 2008).

A preocupação com a violência infantil é muito grande, visto que é nesse período de imensa fragilidade que ocorre o maior desenvolvimento do ser humano. Sendo assim, a ação do profissional da área de Psicologia tem muita relevância na prevenção e no cuidado a vítimas desse tipo de violência, pois por meio de suas atribuições são capazes de promover defesa e proteção integral à criança e ao adolescente (ALBERTO et al., 2008).

A partir de uma revisão da literatura especializada no tema, em bases científicas de dados, como Science Direct, o estudo teve como objetivo reunir e discutir informações a respeito do tema violência contra crianças e adolescentes, abordando os tipos de violência, como essa se apresenta e as possibilidades de atuação do psicólogo no atendimento às vítimas.

\section{Classificação da violência contra a criança e o adolescente}

Ao dissertar sobre violência, é importante perceber o quanto é um problema amplo, apesar de ser comum, e que embora a sociedade viva em crescente globalização e expansão de informação, a violência infantil é algo concreto e atual. É um fenômeno que 
abrange invariavelmente todas as classes sociais, etnias e credos, sendo de difícil apreensão devido ao grau de subjetividade e polissemia em sua expressão (SILVA; MELO, 2018; GUERRA, 2008; ALGERI; SOUZA, 2006).

De acordo com Krug et al. (2002), a Organização Mundial da Saúde (OMS) classifica a natureza dos atos violentos em quatro grupos. São eles: violência física, sexual, psicológica e/ou relacionada à privação ou abandono. Além disso, os mesmos autores informam que pode haver associações desses grupos de violência, como quando a violência é interfamiliar, podendo envolver abuso físico e psicológico, por exemplo.

No Brasil, o ECA descreve, no seu $5^{\circ}$ artigo, que nenhuma criança ou adolescente deve ser objeto de qualquer forma de negligência, exploração, violência, discriminação e opressão ou mesmo ser negado de seus direitos fundamentais. Entretanto, a violência atinge diversas e distintas camadas sociais, de forma injusta, cruel e indiscriminada (BRASIL, 1990).

\section{Violência Física}

Entende-se como violência física aquela que é cometida quando um dano não acidental é causado por uma pessoa que está numa relação de poder com a criança ou adolescente, através do uso da força física ou de algum tipo de arma, promovendo ou não lesões externas, internas ou ambas; é toda ação que possa causar dor física. Recentemente adicionou-se a esse tipo de violência o castigo repetido e não severo (ALGERI; SOUZA, 2006; BRASIL, 2001; GUERRA, 2008).

Minayo (2001) cita como as mais habituais consequências da violência: lesões abdominais, fratura de membros, mutilações, traumatismos cranianos, queimaduras, lesões oculares e auditivas, que podem levar desde a invalidez permanente ou não, até a morte. Existe também uma associação dessas agressões físicas com delinquência e sentimentos vingativos, que promovem raiva, angústia, medo e hostilidade.

A violência física caracteriza-se por se manter repetitiva e com relação proporcional ao aumento de situações de estresse do agressor. É aceita socialmente e utilizada como forma de educar e punir crianças e adolescentes. Muitas vezes o objetivo é propiciar obediência; no entanto, ela não advém da compreensão das normas estabelecidas pelos pais ou responsáveis, mas, sim, do medo imposto através da agressividade e da hostilidade (HART et al., 2008).

\section{Violência Psicológica}

A violência psicológica se constitui como uma interferência negativa sobre a criança ou adolescente ou sobre sua competência social. Pode também ser qualificada como tortura psicológica, quando uma pessoa, numa relação de poder com a criança ou adolescente, constantemente a deprecia, bloqueia seus esforços de autoaceitação e lhe proporciona grande sofrimento mental (CAMARGO; BURALLI, 1998; GUERRA, 2008).

Garbarino, Kostelny e Dubrow (1991) enumeram efeitos gerados por esse tipo de violência e salientam o quanto suas consequências podem ser graves, devido ao fato de ser uma agressão de difícil detecção. Podem ser eles: incapacidade de aprender, de construir e manter relações sociais, comportamento inapropriado, humor depressivo e tendência a desenvolver sintomas psicossomáticos.

Frequentemente, essa violência está presente nas demais e causa sérios danos à identidade e à autoestima, dificultando o processo de desenvolvimento e crescimento da vítima. As caraterísticas mais encontradas nesse tipo de violência são: isolar a criança ou adolescente das experiências comuns, impedindo-a de ter contato com amigos ou levando-a a crer que está sozinha no mundo; desprezar a criança ou adolescente, rejeitar suas necessidades, fazer ameaças, cobranças ou punições exageradas e não estimular seu crescimento, aterrorizá-la e instaurar o medo (BRASIL, 2002; DAY et al., 2003; GUERRA, 1985).

\section{Violência Sexual}

Define-se a violência sexual como todo ato ou jogo sexual, em relação heterossexual ou homossexual, cujo agressor está em estágio de desenvolvimento psicossexual mais avançado que a criança ou adolescente, alcançando prazer sexual através de práticas eróticas e sexuais impostas pela violência física, ameaça, sedução ou indução da vontade, variando desde atos onde não há o contato físico até a outros tipos de ações onde o contato possa existir. Inclui, ainda, a exploração sexual e a pornografia (BRASIL, 2002).

Essa violência é predominante e é registrada em qualquer período histórico, independente de classe social, sendo considerado como um grave problema de saúde pública. Trata-se de uma violação dos direitos humanos e, em sua grande maioria, acontece dentro do ambiente familiar, onde o agressor possui relação parental com a vítima (ADED et al., 2006; AZAMBUJA, 2004; HABIGZANG et al., 2005; CRAMI, 2009).

Em consequência desse tipo de violência pode ocorrer a Síndrome do Segredo, tanto na violência sexual intrafamiliar - cujo agressor possui relação sanguínea ou afetiva com a vítima, como pais biológicos ou adotivos, padrastos, irmãos, tios ou avós -, quanto na extrafamiliar - onde o agressor não pertence a esfera familiar. A criança ou seus familiares (quando têm o conhecimento do ocorrido) ocultam os fatos, com o intuído de manter a rotina daquela criança ou do lar (BALBINOTTI, 2009).

Alguns fatores externos e internos podem resultar nessa síndrome, como: quando há falta de elementos médicos que comprovem o abuso; no caso da acusação verbal da criança e sua falta de credibilidade; por 
consequências ou ameaças físicas; no medo e culpa. Esses últimos são as mais comuns reações dessas vítimas, devido à crença de que são responsáveis pelo ato vivido. Além de, muitas vezes, serem obrigadas a prosseguir o convívio com o agressor e a estarem expostas a reincidência do abuso (FURNISS, 1993; BALBINOTTI, 2009).

\section{Negligência e Abandono}

A negligência é o tipo de violência mais difícil de conceituar, pois ela atravessa questões culturais, sociais e familiares e, segundo Faleiros, Mathias e Bazon (2009) é a forma que mais acomete crianças e adolescentes. Nesse contexto, a privação materna é o estressor mais relevante e afeta significativamente o desenvolvimento da criança. A experiência de violência na primeira década de vida, grande parte das vezes, é motivadora de diversos desvios psicológicos; sendo assim, observa-se que quanto menor a idade, maior é a vulnerabilidade à violência e às suas consequências.

A negligência consiste na omissão familiar em promover necessidades físicas e emocionais. E o abandono, na forma mais cruel de negligência. Caracterizam-se pelas falhas, geradas por pais ou responsáveis, em prover alimentação, vestimenta, medicação e educação (CAMARGO, BURALLI, 1998).

Correspondem a sentimentos e a ações de indiferença e descompromisso, além de desinteresse com relação às necessidades básicas da criança e do adolescente. É a porta de entrada para outras violências e faz com que a vítima não construa referências a respeito de afeto, carinho e cuidado necessários a um crescimento saudável, desmotivando seu desenvolvimento intelectual, podendo colocá-la em situação de vulnerabilidade (ROSENBURG, 2011).

Além dos quatro grupos de violência definidos pela OMS, Minayo (2001) acrescenta o conceito de violência estrutural, relacionado à condição de vida da criança e do adolescente que, em função de decisões histórico-econômicas e sociais, estão vulneráveis às condições miseráveis de vida. Nota-se a grande desigualdade social que a sociedade brasileira vive, evidenciada pelas situações desfavoráveis de vida dessas crianças vitimizadas. A exemplo desse aspecto cruel da violência estrutural, estão as crianças moradoras de rua, que estão à mercê do uso indiscriminado de drogas, do trabalho infantil e da exploração, do envolvimento com atos criminosos e da prática de sexo inseguro e comercializado. São crianças e adolescentes vítimas de uma sociedade excludente, que não possuem seus direitos de convivência familiar e comunitária respeitados, o que seria fundamental para sua formação, desenvolvimento emocional, físico e psíquico.

\section{Como a violência contra a criança ou adolescente se apresenta}

A violência infantil faz parte do cotidiano brasileiro de tal forma que alcançou relevância política e visibilidade social. Com a implementação do ECA foi possível garantir às crianças a identificação e a denúncia das situações de violência, habilitando ao Estado instrumentos legais de proteção, mesmo em casos de suspeita (BRASIL, 1990).

Em 2006, o Ministério da Saúde implementou a Vigilância de Violência e Acidentes (VIVA), com duas frentes: Vigilância por Inquérito, através de uma pesquisa nas portas de entrada de emergências de municípios selecionados; e Vigilância Contínua, realizada a partir de notificações compulsórias das violências. Inicialmente, o sistema se restringia apenas às maternidades e serviços de atendimento às doenças sexualmente transmissíveis e especializados; porém, em 2009, se estendeu para todo o serviço de saúde. Em 2010 foram feitas 1.496 notificações e, em 2014, os números contabilizaram um total de 3.000 notificações, o que amplia a compreensão do fenômeno violência no Brasil (BRASIL, 2013).

As crianças ou adolescentes vítimas do abuso físico contínuo sofrem com problemas de comportamento e sintomas psiquiátricos. Muitas vezes essas vítimas são incapazes de incorporar na memória os elementos sensoriais e emocionais do evento, havendo então uma fragmentação da realidade, cujo fenômeno é denominado dissociação (MAIA; MOREIRA; FERNANDES, 2009; STERNBERG, 1993).

A dissociação é caracterizada por distorções na percepção temporal, espacial, corporal e de consciência da experiência durante e imediatamente após o acontecimento traumático. E o sistema dissociativo possui estreita relação com problemas de saúde mental encontrados em vítimas de violência, como o transtorno de estresse pós-traumático (TEPT) (MARMAR; WEISS; METZLER, 1997).

O transtorno de estresse pós-traumático (TEPT) pertence à categoria dos transtornos de ansiedade e, por definição, está relacionado à exposição a um episódio estressor traumático, onde a vítima reage com acentuado conteúdo emocional, relacionado a dor, pavor e medo. O trauma é definido como um dano ao estado psíquico ou comportamental, causado por estresse mental, emocional ou lesão física, relacionados a eventos que podem provocar medo agudo ou crônico (GARBARINO; KOSTELNY; DUBROW, 1991).

O TEPT acomete crianças e adolescentes após eventos pessoais, testemunho ou conhecimentos de fatos onde há risco de vida ou integridade física próprio ou a terceiros. A Associação de Psiquiatria Americana (APA) identifica a TEPT através do aparecimento de sintomas 
após a exposição a um episódio traumático que cause medo intenso, impotência ou terror, envolvendo morte e agressões reais, onde o estressor é considerado como ameaçador à vida (APA, 2002).

A APA (2002) divide os principais sintomas em três grandes grupos:

I - Reviver o evento traumático, a partir de lembranças angustiantes e recorrentes, como nos sonhos e em flashbacks, onde a pessoa age e sente como se aquilo estivesse acontecendo novamente, entre outros sintomas;

II - Esquiva persistente de elementos associados ao evento, como esforços para bloquear os pensamentos e sentimentos, evitando locais, pessoas e ações que recordem o evento, entre outros sintomas;

III - Excitabilidade aumentada, através surtos de raiva, insônia, irritabilidade, falta de concentração, entre outros sintomas. Entretanto, somente podemos caracterizar como TEPT os casos em que os sintomas estejam ocorrendo há mais de um mês e causem sofrimento e prejuízo em áreas importantes da vida.

O TEPT pode acometer qualquer idade, sendo mais comum que os sintomas apareçam em até três meses depois de o fato ocorrido. Evidências informam que sua ocorrência não necessariamente está conectada a apenas um evento, e outros fatores de vulnerabilidade podem estar associados e precisam ser avaliados, tais como histórico familiar, tipo de personalidade, transtornos comportamentais pré-existentes e também o histórico de depressão de parentes em primeiro grau (XIMENES et al., 2009)

As expressões de TEPT em crianças pequenas possui uma singularidade que dificulta o diagnóstico: a dificuldade de descrever os sintomas, visto que essa narração exige habilidade no relato verbal. Por esse motivo, essas vítimas demonstram seus sintomas nos primeiros anos de vida através de uma ansiedade generalizada, com medo de monstros e pessoas estranhas, distúrbios do sono e uso de imagens ou símbolos por meio de desenhos que possam ter relação com o trauma ocorrido (SCHEERINGA et al., 1995).

Ximenes et al. (2009) informa que existem outras formas de demonstração de TEPT em crianças ou adolescentes, como um comportamento desorganizado ou agitado, um sentimento de futuro encurtado associado com a ideia de que não chegará à idade adulta, além de sintomas físicos, como dores de cabeça e enjoos. Esses eventos podem ser revividos através de sonhos ameaçadores, com monstros e solidão. Os episódios não somente afetam a vida das pessoas acometidas, como também de seus familiares e comunidade, tendo expressiva relevância na saúde e na segurança públicas.

Entretanto, nem todas as crianças submetidas a eventos traumáticos irão desenvolver TEPT, devido ao fato de que outros elementos como ambientais, contextuais e a própria história de vida da vítima contribuem para o desenvolvimento ou não do transtorno. Algumas crianças e adolescentes possuem capacidades diferenciadas, em função das quais, apesar de estarem em situações de risco, conseguem enfrentá-lo sem prejuízo a sua saúde mental (MARSH; GRAHAM, 2007).

\section{Atuação do Psicólogo no Atendimento à Criança e ao Adolescente Vítima de Violência}

$\mathrm{Na}$ proteção da criança e do adolescente contra a violência e atenuação dos danos por ela causados, os profissionais de Psicologia têm papel fundamental, pois além de sua função protetiva, possuem também potencial para auxiliar nos prejuízos psicológicos causados nas vítimas. No início dos anos 1980, o psicólogo foi incluído no serviço público de saúde, o que permitiu ampliar e diversificar a sua atuação. E a partir da sua introdução nas instituições e comunidades, tornou possível o atendimento à todas as classes sociais e a criação de estratégias de intervenção, terapias comunitárias e campanhas socioeducativas (DUTRA, 2004; MURTA; MARINHO, 2009).

Em qualquer fase da infância existe gravidade na violência; traumas físicos e emocionais deixam sequelas que terão impacto na idade adulta. As crianças e os adolescentes que sofreram maus-tratos estão mais propícios a episódios de violência escolar e a transgressões das normas sociais, que podem compor um círculo de violência. Nesse contexto, percebe-se a importância da atuação do profissional de Psicologia, na tentativa de amenizar os danos causados a essas vítimas, tendo em vista que são capazes de compreender os sentidos e significados que as pessoas atribuem às suas vidas de modo sensível e humano (SILVA; MELO, 2018; KLIPPEL; CAMARGO, 2015).

No atendimento às vítimas de violência são necessárias integrações em diferentes frentes de atuação, como o Conselho Tutelar, Juizado Especial, Centro de Referência Especial da Assistência Social (CREAS), Centro de Referência da Assistência Social (CRAS) e outros centros especializados. É fundamental a melhoria desse trabalho coletivo com a intenção de garantir a preferência absoluta da proteção integral às crianças e adolescentes vítimas. É muito importante que os profissionais envolvidos, principalmente os psicólogos, se conscientizem de sua função, a fim de reestabelecer os direitos violados (CARVALHO; LUZ; ASSIS, 2007).

Durante o atendimento ou acompanhamento de casos de violência contra a criança, é essencial acolhêla, dando a ela o espaço e o tempo necessários para que possa refletir, elaborar e compartilhar os eventos 
sofridos. Não importa a maneira como a história seja contada ao profissional - a vítima precisa ser respeitada e escutada como detentora da verdade e de sua realidade psíquica (PRADO et al., 2004). Existe um movimento de estímulo durante o processo de escuta profissional e de narrativa da vítima, visto que o conteúdo verbalizado, ou não, está diretamente relacionado com o acolhimento que o psicólogo direciona a estes casos (FURNISS, 1993).

A escuta da criança que possa ter sofrido alguma violência requer cuidado e uma formação específica que assegure o pleno entendimento do ocorrido. $\mathrm{Na}$ perspectiva de proteção às vítimas, o papel do psicólogo ultrapassa a simples soma de informações, o que torna muito importante sua sensibilidade e empatia para que consiga compreender a experiência da criança, possibilitando um trabalho multidisciplinar que garanta a proteção dos direitos da criança e também a atenção ao seu estado subjetivo, em função das vivências traumáticas (MAYER; KOLLER, 2002; FRONER; RAMIRES, 2008).

Sendo assim, é imprescindível ouvir a vítima com atenção e cautela, mantendo o profissionalismo, com o propósito de evitar novos prejuízos psicológicos. É importante que o profissional trace metas de intervenção seguras e eficazes, e que trabalhe sob a ótica de que a criança e o adolescente precisam de políticas sociais básicas que possam garantir sua proteção integral e essencial para seu desenvolvimento (BALBINOTTI, 2009; NUNES SALES, 2015).

Froner e Ramires (2008), indicam que o profissional deve levar em conta a experiência vivenciada pela vítima e a tensão psíquica a ela vinculada; sua postura não deve ser julgadora ou punitiva, sendo essencial uma relação de confiança, na qual se sustentará o acompanhamento subsequente.

A superação da violência infantil ou adolescente depende de ações planejadas, eficazes e bem direcionadas no sentido de valorização e resgate do ser humano. São relevantes os trabalhos em forma de rede, através da criação de estratégias de enfrentamento dos episódios violentos, de suas particularidades e de sua prevenção, com lutas coletivas. Pode-se dividir a prevenção em três grupos, prevenção primária (estratégias para a população a fim de diminuir a incidência), prevenção secundária (com a identificação precoce dos grupos de risco) e prevenção terciária (voltada aos agressores e às vítimas, com a intenção de reduzir consequências e de evitar que o indivíduo sofra o processo de incapacidade permanente (GUERRA, 2008).

É essencial a presença de profissionais de saúde mental nos três níveis de atenção à saúde, assim como a implementação de programas e ações coletivas e preventivas, inerentes à violência contra criança e ao adolescente, juntamente com a promoção dos direitos infantis pelos setores públicos (BAGAGI; PAIVA,
2012). Também é de extrema relevância a atuação do profissional de Psicologia na pesquisa, que viabiliza identificar as falhas presentes nos serviços disponíveis, no combate a violência infantil e adolescente, a fim de promover melhorias no atendimento e, consequentemente, o bem-estar das vítimas. Uma formação sólida em Psicologia capacita o profissional para lidar com as dificuldades e a dinâmica dos casos, o que envolve a relação com profissionais de diferentes áreas, tais como advogados e assistentes sociais, e requer uma formação multidisciplinar e a manutenção de atualizações constantes, que possibilitem lidar com situações distintas (MAYER; KOLLER, 2002; FRONER; RAMIRES, 2008).

Guerra (2008) argumenta que a criança e o adolescente precisam ser encarados como sujeitos de direitos, visto que uma criança ou adolescente vitimado pela violência precisa ser considerado como um sujeito que teve seus direitos violados, em função de sua vulnerabilidade, e que precisa ser cuidado e protegido.

Nesse contexto, os psicólogos estão capacitados para entender os processos mentais do comportamento humano, sendo assim, são essenciais no processo de ajuda e de acolhimento à vítima. A violência infantil e adolescente é uma realidade e requer atenção das políticas públicas e dos profissionais de saúde.

\section{Considerações Finais}

O estudo permitiu identificar a diversidade e a complexidade das formas de violência cometida contra a criança e o adolescente. A OMS aponta para: a violência física - oriunda do emprego da força física ou pelo uso de algum objeto, gerando alguma lesão à vítima; no meio social, usualmente, é recorrente, com a justificativa de ser um método corretivo e/ou punitivo; a violência sexual - na qual o agressor possui um desenvolvimento psicossexual mais adiantado que a vítima, seja realizando contato físico ou outro tipo de exploração sexual; nesse tipo de violência a síndrome do Segredo é recorrente; a violência psicológica - de uma maneira geral, é uma interferência depreciativa à vítima, bloqueando seu desenvolvimento, além de ser uma agressão de maior complexidade de detecção; e a negligência e o abandono - que é comumente identificada, embora não seja de simples conceituação, uma vez que envolve questões culturais e sociais.

Diversas podem ser as consequências desses atos de violência na vida da criança e do adolescente, como o transtorno pós-traumático, que pode ocorrer em qualquer idade. E torna-se evidente que os problemas causados por qualquer violência são um fator de risco no progresso de desenvolvimento da criança e do adolescente. 
Nesse cenário, a atuação dos profissionais da saúde, em especial do psicólogo, possui um papel fundamental no auxílio às vítimas. Esse pode assistir a vítima tanto na prevenção da violência como atenuar os danos ocasionados por ela. Além disso, melhorias nos órgãos da rede de proteção à criança e ao adolescente são imprescindíveis.

\section{Referências}

ADED, N. I. O, et al. Abuso sexual em crianças e adolescentes: uma revisão de 100 anos de literatura. Revista de Psiquiatria Clínica, v. 33, p. 204-213, 2006

ALBERTO, M. F. P. Dimensões subjetivas do trabalho precoce e meninos em condição de rua em João Pessoa (PB). Tese de Doutorado em Sociologia, Universidade Federal de Pernambuco, Recife, 2002.

ALBERTO, M. F. A. P., et al. O papel do psicólogo e das entidades junto a crianças e adolescentes em situação de risco. Revista Psicologia, Ciência e Profissão, v. 28, n. 3, p. 558-573, 2008.

ALGERI, S.; SOUZA, L, M. Violência contra crianças e adolescentes: um desafio no cotidiano da equipe de enfermagem. Revista Latino Am. Enfermagem, São Paulo, v. 14, p. 50-57, julho/agosto 2006.

ASSOCIAÇÃO DE PSIQUIATRIA AMERICANA (APA). Manual diagnóstico e estatístico de transtornos mentais: DSM-IVTR ${ }^{\mathrm{TM}}$. Porto Alegre: Artes Médicas; 2002.

AZAMBUJA, M. R. F. Violência sexual intrafamiliar: é possível proteger a criança? Porto Alegre: Livraria do Advogado, 2004.

BAGAGI, P.; PAIVA, C. N. A atuação dos profissionais de saúde nos casos de violência contra crianças e adolescentes. Revista Científica Eletrônica de Pedagogia, Garça / São Paulo, a. X, n. 20, julho, 2012

BALBINOTTI, C. A violência sexual infantil intrafamiliar: a revitimização da criança e o adolescente vítimas de abuso. Revista Direito \& Justiça, Rio Grande do Sul, v. 35, n. 1, jan./jun., 2009.

BRASIL. Presidência da República. Lei n. 8.069, de 13 de julho de 1990. Dispõe sobre o Estatuto da Criança e do Adolescente e dá outras providências. Brasília: Diário Oficial da União, 1990.

Ministério da Saúde. Portaria GM/MS nº 737 de 16 de maio de 2001. Dispõe sobre Política Nacional de Redução da Morbimortalidade por Acidentes e Violências. Brasília: Diário Oficial da União, 2001.

. Ministério da Saúde. Secretaria de Assistência à Saúde. Notificação de Maus-tratos contra crianças e adolescentes pelos profissionais de saúde: um passo a mais na cidadania em saúde / Ministério da Saúde, Secretaria de Assistência à Saúde. Brasília: Ministério da Saúde, 2002.

Ministério da Saúde (MS). Secretária de Vigilância em Saúde. Departamento de Vigilância de Doenças e Agravos não Transmissíveis e Promoção da Saúde. Sistema de Vigilância de Violências e Acidentes (VIVA): 2009, 2010 e 2011. Brasília, 2013.

CAMARGO, C. L.; BURALLI, K. O. Violência familiar contra crianças e adolescentes. Salvador (BA): Ultragraph; 1998.

CARVALHO, L. N.; LUZ, I. C.; ASSIS, N. Rede de atenção a mulheres, crianças e adolescentes em situação de violência: movimento social ou gestão intersetorial de serviços? In: OLIVEIRA, M. L.; SOUSA, S. M. G. (Eds.). (Re)Descobrindo as faces da violência sexual contra crianças e adolescentes. Goiânia: Cânone, 2007. p.19-51.

CRAMI. Centro Regional de Maus-Tratos na Infância. Abuso sexual doméstico: atendimento às vítimas e responsabilidade do agressor. 3. ed. São Paulo/Brasilia: Cortez/ Unicef, 2009. Série Fazer Valer os Direitos, v.1.

DAY, V. P. et al. Violências domésticas e suas manifestações. Revista de Psiquiatria, Rio Grande do Sul, v.25, n. 1, p. 9-21, abril, 2003.

DOSSI, A. P. et al. Perfil epidemiológico da violência física intra-familiar: agressões denunciadas em um município do estado de São Paulo, Brasil, entre 2001 e 2005. Cad. Saúde Pública, Rio de Janeiro, v. 24, n. 8, p. 1939 1952, ago., 2008.

DUTRA, E. Considerações sobre as significações da psicologia clínica na contemporaneidade. Estudos de Psicologia, Natal, v. 9, p. 381-387, 2004.

FALEIROS, J. M.; MATIAS, A. S. A.; BAZON, M. R. Violência contra crianças na cidade de Ribeirão Preto, São Paulo, Brasil: a prevalência dos maus-tratos calculados com base em informações do setor educacional. Caderno de Saúde Pública, São Paulo, v. 25, n. 2, p. 337-348, 2009.

FERREIRA, K. M. M. Violência doméstica/intrafamiliar contra crianças e adolescentes - nossa realidade. In: SILVA, L. M. P. (org.) Violência doméstica contra a criança e o adolescente. Recife: EDUPE, 2002. p. 17-43.

FERRIANI, M. G. C.; BERTOLUCCI, A. P.; SILVA, M. A. I. Assistência em saúde às criancas e adolescentes abrigados em Ribeirão Preto, SP. Rev Bras Enferm, São Paulo, v. 61, n. 3, p. 342-348, 2008.

FRONER, J. P.; RAMIRES, V. R. Escuta de crianças vítimas de abuso sexual no âmbito jurídico: uma revisão crítica da literatura. Paidéia, Ribeirão Preto, v. 18, n. 40, 2008

FURNISS, T. Abuso sexual da criança: uma abordagem multidisciplinar. Porto Alegre, RS: Artes Médicas, 1993.

GARBARINO, J.; KOSTELNY, K.; DUBROW, N. What children can tell us about living in danger? American Psychologists, v. 46, n. 4, p. 376-383, 1991.

GÓES, J. R.; FLORENTINO, M. Crianças escravas, crianças dos escravos. In: DEL PRIORE, M. (Org.). Histórias das crianças no Brasil. São Paulo: Contexto, 2002. p. 177-191.

GONÇALVES, H. S.; FERREIRA, A. L. A notificação da violência intrafamiliar contra crianças e adolescentes por profissionais de saúde. Cad Saúde Pública, v. 18, p. 315-319, 2002.

GUERRA, V. N. A. Violência de pais contra filhos: procuram-se vítimas. São Paulo (SP): Cortez; 1985

Violência de Pais contra Filhos: a tragédia revisitada. 6. ed. São Paulo: Cortez, 2008.

HABIGZANG, L. F. et al. Abuso sexual infantil e dinâmica familiar: aspectos observados em processos judiciais. Revista Psicologia: Teoria e Pesquisa, v. 21, p. $341-348,2005$

HART, S. N. (Org.) O caminho para uma disciplina infantil construtiva: eliminando castigos corporais. São Paulo: Cortes, Brasilia DF: Unesco, 2008 .

HUSSEY, J. M.; CHANG, J. J.; KOTCH, J. B. Child maltreatment in the United States: prevalence, risk factors, and adolescent health consequences. Pediatrics, v. 118, p. 933-42, 2006.

KLIPPEL, Y. A. M., CAMARGO, D. Processo participativo entre profissionais de saúde para integrar o atendimento à criança vítima de violência. Revista Pesquisas e Práticas Psicossociais, São João Del-Rei, v. 10 , n. 2 , jul/dez, 2015

KRUG, E. G et al. (edit.) World report on violence and health. Geneva: WHO; 2002

MAIA, A. C.; MOREIRA, S. H.; FERNANDES, E. Adaptação para a língua portuguesa do Questionário de Experiências Dissociativas Peritraumáticas (QEDP) numa amostra de bombeiros. Revista de psiquiatria clínica, São Paulo, v. 36, n. 1, p. 1-9, 2009.

MARMAR, C.; WEISS, D.; METZLER, T. The Peritraumatic Dissociative Experiences Questionnaire. In: WILSON, J; KEANE, T (editors). Assessing Psychological Trauma and TEPT: The Guilford Press; p. 412-28, 1997.

MARSH, E. J.; GRAHAM, S. A. Psicopatologia e tratamento do transtorno de estresse pós-traumático. In: CABALLO, V. E.; SIMÓN, M. A.. Manual de Psicologia Clínica Infantil e do Adolescente. São Paulo: Santos, 2007, p. $30-51$.

MAYER, L. R.; KOLLER, S. H. Rede de apoio social e representação mental das relações de apego de crianças vítimas de violência doméstica. Violência Contra Crianças e Adolescentes. Teoria, pesquisa e prática. São Paulo: Grupo A, 2002. p. 55-68. 
MINAYO, M. C. S. Violência contra crianças e adolescentes: questão social, questão de saúde. Revista Bras. Saúde Mater. Infant., Recife, v. 1, n. 2, maio/ ago, 2001.

MOURA, E. B. B. Crianças operárias na recém-industrializada São Paulo. In: DEL PRIORE, M. (Org.). Histórias da criança no Brasil. 6. ed. São Paulo: Contexto: 2009. p. 259-288

MURTA, S, G.; MARINHO, T. P. C. A Clínica Ampliada e as Políticas de Assistência Social: uma Experiência com Adolescentes no Programa de Atenção Integral à Família. Revista Eletrônica de Psicologia e Políticas Públicas, v.1, n. 1, 2009.

NUNES, A. J.; SALES, M. C. V. Violência contra crianças no cenário brasileiro. Revista Ciência \& Saúde Coletiva, v. 21, n. 3, p. 871-880, 2015.

PRADO, M. C. C. A. et al. O mosaico da violência. São Paulo: Vetor, 2004.

RAMOS, F. P. A história trágico-marítima das crianças nas embarcações portuguesas do século XVI. In: DEL PRIORE, M. (Org.). Histórias das crianças no Brasil.. São Paulo: Contexto, 2002. p. 19-54.

ROSENBURG, E. G. Representações sociais de violência doméstica contra crianças e adolescentes em educadores: denúncia, notificação ou omissão? Tese apresentada a Faculdade de Filosofia, Ciências e Letras, USP. Ribeirão Preto, 2011.

REICHENHEIM, M.E. et al.. Violence and injuries in Brazil: the effect, progress made, and challenges ahead. Lancet, 377:1962-75, 2011.

SCHEERINGA, M. S. et al. Two approaches to the diagnosis of posttraumatic stress disorder in infancy and early childhood. Journal Am Acad Child Adolesc Psychiatry, v. 34, p. 191-20, 1995.

SILVA, J. C. T.; MELO, S. C. A. Violência Infantil: atuação do psicólogo no processo de auxílio à criança. Revista Psicologia Saúde e Debate, v. 4, n. 1, p. 61-84, Fev, 2018

STERNBERG, K. J, et al. Effects of domestic violence on children's behavior problems and depression. Developmental Psychology, v. 29, p. 44-52, 1993.

VENÂNCIO, R. P. Os aprendizes da guerra. In: DEL PRIORE, M. (Org.). Histórias das crianças no Brasil. São Paulo: Contexto, 2002, p. 192-209.

XIMENES, L. F. et al. Violência e transtorno de estresse pós-traumático na infância. Revista Ciência \& Saúde Coletiva, Rio de Janeiro, v. 14, n. 2, p. 417-433, 2009. 